\title{
PERANCANGAN SISTEM APLIKASI PENITIPAN HEWAN WIYADI PET SHOP BERBASIS JAVA
}

\author{
Lucky Ramadhan $^{1}$, Nur Alamsyah ${ }^{2}$ \\ 1,2Informatika, Fakultas Teknik dan Ilmu Komputer, Universitas Indraprasta PGRI \\ Jalan Raya Tengah No 80, Kelurahan Gedong, Pasar Rebo, Jakarta Timur \\ ㄴ.1uckyramadhan76@gmail.com, ${ }^{2}$ alamcbr11@gmail.com
}

\begin{abstract}
ABSTRAK
Tujuan penelitian ini untuk Meningkatkan pelayanan terhadap konsumen dalam transaksi saat berkunjung ke toko wiyadi petshop, Memudahkan perusahaan dalam hal pencatatan data transaksi, laporan dan pendataan lainnya. Adapun metode yang penulis lakukan dengan mengguanakan cara kualitatif dengan metode pengumpulan data untuk mendapatkan data-data serta informasi untuk mendukung penyempurnaan hasil dari penelitian ini antara lain dengan melakukan studi lapangan, Studi Literatur Pengumpulan data dan informasi yang di butuhkan.Untuk perancangan sistem aplikasi penitipan hewan menggunakan alat bantu yaitu Unified Modelling Leanguage (UML) dan MySQL sebagai databasenya. Dapat disimpulkan,sistem aplikasi penitipan hewan meningkatkan kinerja Toko Wiyadi PetShop selain itu memberikan alternatif baru untuk meningkatkan kepercayaan pelanggan terhadap Wiyadi Pet Shop melalui pelayanan yang lebih cepat lagi.
\end{abstract}

Kata kunci : Sistem Informasi,Transaksi Penjualan, Toko Wiyadi Pet Shop.

\begin{abstract}
The purpose of this study is to improve service to consumers in transactions when visiting the wiyadi petshop shop, making it easier for companies to record transaction data, reports and other data collection. The method that the author uses is using qualitative methods with data collection methods to obtain data and information to support the improvement of the results of this research, among others, by conducting field studies, Literature Studies, collecting data and information needed. For designing animal care application systems using tools, namely Unified Modeling Leanguage (UML) and MySQL as the database. It can be concluded, the animal care application system improves the performance of the Wiyadi Pet Shop Shop in addition to providing a new alternative to increase customer trust in the Wiyadi Pet Shop through even faster service.
\end{abstract}

Key Word: Information Systems, Sales Transactions, Wiyadi Pet Shop Shop.

\section{PENDAHULUAN}

Memelihara hewan peliharaan pada saat ini sudah menjadi gaya hidup (life style) bagi sebagian besar masyarakat Indonesia. Hingga saat ini semakin banyak masyarakat Indonesia yang memiliki hewan peliharaan, maka semakin bekembang juga proses bisnis.

Penggunaan komputer dalam penanganan dan pengolahan data memerlukan suatu prosedur yang tepat, dalam hal ini adalah perangkat lunak aplikasi atau disebut juga program. Pengolahan data yang tepat dan cepat mampu meningkatkan kinerja (Yusuf et al., 2021).

Aplikasi berbasis desktop berguna untuk memberikan kemudahan bagi pengguna komputer atau laptop dalam mengelola data sehingga mampu menghasilkan sebuah laporan yang cepat, tepat, dan akurat. Meskipun saat ini banyak pengguna sudah mulai beralih ke aplikasi berbasis smartphone, baik itu Android maupun iOS, penggunaan aplikasi berbasis desktop masih efektif untuk digunakan. Hal tersebut disebabkan oleh keterbatasan perangkat yang mendukung aplikasi berbasis Android ataupun iOS untuk mencetak laporan (Kurniawan \& Syahputra, 2018).

Banyak dari konsumen yang memakai jasa penitipan hewan peliharaan ketika disibukan dengan kegiatan rumah, pekerjaan kantor, ataupun keluar kota, maka dari itu diperlukannya jasa penitipan hewan tersebut. Akan tetapi perusahaan pada jasa penitipan hewan itu sendiri masih banyak yang melakukan pengolahan data dan transaksi dilakukan secara manual dan belum terkomputerisasi sehingga dapat memakan waktu yang cukup lama. Dan juga dalam pembuatan laporan yang memerlukan pencatatan ulang dari setiap berkas dan data fisik tidak dilakukan secara otomatis sehingga 
menyebabkan terjadinya kesalahan pencatatan data dan penggandaan data.

Berdasarkan latar belakang masalah yang sudah dikemukakan maka rumusan masalah yang dikaji dalam tugas akhir ini adalah perancangan sistem aplikasi penitipan hewan Wiyadi Pet Shop.

Menurut Wahana Komputer dalam Arizona \& Kaunen (2017) "Netbeans adalah IDE (Integred Development Environment) open source yang seringkali diasosiasikan dengan java”. Lisnawanty. (2014)

Berbasis Java ini dalam software Apache NetBeans, merancang program aplikasi penitipan hewan berbasis java ini dengan menggunakan software Apache NetBeans, perancangan sistem aplikasi penitipan hewan Wiyadi Pet Shop Berbasis Java ini dalam software Apache NetBeans.

Menurut Budiharto dalam Arizona \& Kaunen (2017) "Java adalah sebuah bahasa pemograman dan platform yang handal untuk mengambangkan aplikasi enterprise yang didesain untuk menjadi suatu bahasa kecil, mudah dan portabel terhadap berbagai platform". (Lisnawanty. (2014)

Manfaat dari penelitian sebagai tugas akhir ini adalah Meningkatkan pelayanan terhadap konsumen dalam transaksi,Memudahkan perusahaan dalam hal pencatatan data transaksi, pembuatan laporan dan pendataan lainnya, Memanfaatkan hasil program sedemikian rupa agar dapat digunakan oleh siapa pun sebagai bahan referensi dasar dalam membuat suatu program.

Pengertian database menurut Chan. 2017. (2017). Membuat Aplikasi Database dengan PowerBuilder 12.6 dan MySQL. Jakarta: PT Alex Media Komputindo.

Penelitian oleh (Supriyanta \& Nurhayati, 2018) dengan judul Sistem Informasi Penjualan Secara Online Studi Kasus Pada Mechin Petshop Yogyakarta. Hasil dari penelitian tersebut adalah Untuk membantu sistem penjualan Mechin Petshop agar lebih efektif dan efisien kepada pelanggan.

Memberikan informasi yang jelas kepada pelanggan dan juga untuk meningkatkan transaksi penjualan dengan mendapatkan keuntungan agar usaha tersebut meningkat. Penelitian selanjutnya oleh Fikri, W (2017) dengan judul Sistem Pelayanan Hewan Berbasis Web Pada Zoom Pet Care, hasil dari penilitan tersebut adalah dengan dirancangnya sistem informasi akutansi penjualan yang mempermudah proses transaksi penjualan, pembelian dan operasional sehingga memperkecil kesalahan pencatatan dana yang masuk dan keluar untuk memberikan informasi yang akurat tentang pelayanan yang ada di petshop untuk memudahkan pelanggan mengetahui pelayanan yang diberikan di petshop

\section{METODE PENELITIAN}

Metode penelitian yang digunakan oleh penulis adalah metode penelitian kualitatif. Metode penelitian kualitatif adalah pengumpulan data pada suatu latar alamiah dengan maksud menafsirkan fenomena yang terjadi dimana peneliti adalah sebagai instrumen kunci (Anggito \& Setiawan, 2018).

\section{Metode pengumpulan data}

Metode pengumpulan data yang dilakukan oleh penulis untuk mendapatkan data-data serta informasi untuk mendukung penyempurnaan hasil dari penelitian ini antara lain:

\section{Studi Lapangan}

Studi lapangan ini penulis lakukan untuk melihat langsung terhadap sistem pelayanan kegiatan penitipan hewan di Wiyadi petshop. Dalam studi lapangan ini dipergunakan teknik pengumpulan data antara lain dengan cara:

1. Observasi

Observasi adalah cara menghimpun data data yang akan digunakan datanya untuk melakukan pengamatan dan pencatatan secara tersturktur terhadap objek yang akan diteliti. (Listiawan, T, 2016).

Penulis mempelajari dan mengamati proses-proses yang terdapat pada Wiyadi petshop di Jl. Cipayung Raya No.34, Kec. Cipayung, Kota Jakarta Timur, Daerah Khusus Ibukota Jakarta Timur 13840. Pada bulan Maret 2021 samapai dengan bulan Juli 2021, prosesnya antara lain :

a. Proses Pendaftaran

Penulis mengamati porses pendaftaran pelanggan pada Wiyadi Petshop mulai dari kedatangan pelanggan sampai dengan proses pemeriksaan hewan

b. Proses Pelayanan Penitipan Hewan 
Penulis mengamati proses pelayanan penitipan hewan yang ada di Wiyadi Petshop.

c. Proses Pembuatan Laporan

Penulis mengamati proses pembuatan laporan yang dilakukan oleh admin, mulai dari pengecekan laporan sampai dengan cetak laporan.

\section{Studi Literatur}

Pengumpulan data dan informasi yang penulis lakukan untuk perancangan sistem aplikasi penitipan hewan adalah dengan cara Mempelajari buku-buku literatur mengenai menganalisis dan mendesain sebuah sistem,Mempelajari sistem dari aplikasi penitipan hewan yang serupa dengan aplikasi yang akan dibuat, Mempelajari buku-buku panduan tentang pemrograman Java untuk menginterasikannya dengan MySQL sebagai databasenya.

\section{HASIL DAN PEMBAHASAN \\ Analisa Permasalahan}

Sistem penjualan Pelayanan Jasa Penitipan Hewan di WIYADI Petshop masih tergolong sederhana. Pencatatan data pelanggan, data hewan dilakukan secara manual dan berdasarkan penulisan tangan, sehingga besar kemungkinan terjadinya kesalahan didalam pembuatan laporan. Begitu pula dalam hal penyimpanan data, data tersimpan dalam map dan diletakkan dilemari arsip.

\section{Alternatif Penyelesaian Masalah}

Setelah mengetahui masalah-masalah yang terdapat dalam proses pendataan serta pembuatan laporan pada Wiyadi petshop maka penulis mengusulkan pemecahan masalah untuk meningkatkan mutu pelayanan pada toko tersebut diperlukan sistem terkomputerisasi pada pengelolaan data dan proses transaksi pelayanan pada Wiyadi petshop. Sistem ini akan dibuat oleh penulis berbentuk aplikasi desktop yang dibuat menggunakan bahasa pemrograman java dengan penyusunan menggunakan aplikasi netbeans dan database $M y S Q L$.

\section{Unified Modeling Language (UML) Sistem yang Diusulkan}

Menurut (Sukamto \& Shalahuddin, 2015) "UML Merupakan bahasa visual untuk pemodelan dan komunikasi mengenai sebuah sistem dengan menggunakan diagram dan teks-teks pendukung”. (Rohman, F., Yanto, A. B. H. Y., \& Sutarsih, N., 2018)

Secara sederhana, UML memiliki arti sebagai pendekatan modern untuk pemodelan serta untuk mendokumentasikan perangkat lunak. Pada zaman modern ini UML menjadi suatu teknik pemodelan proses bisnis yang sangat populer.

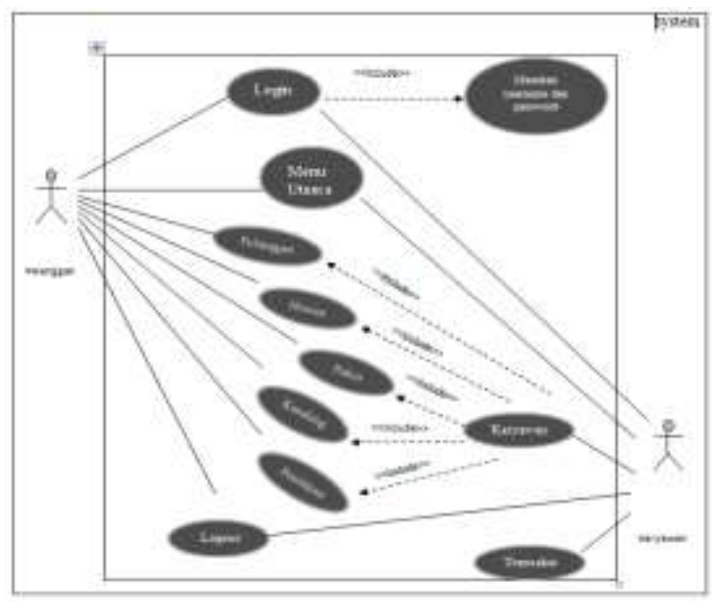

Gambar 1. Use Case Diagram

\section{Tampilan Layar \\ Tampilan Login}

Tampilan form Login ini muncul di awal saat pengoperasian program aplikasipenitipan hewan wiyadi pet shop untuk diisi oleh admin sebagai user. Masukkan username dan password yang sesuai dengan hak akses supaya bisa mengoperasikan sistem aplikasi penjualan benih sayuran. Jika username dan password sesuai maka akan masuk ke tampilan menu utama admin.

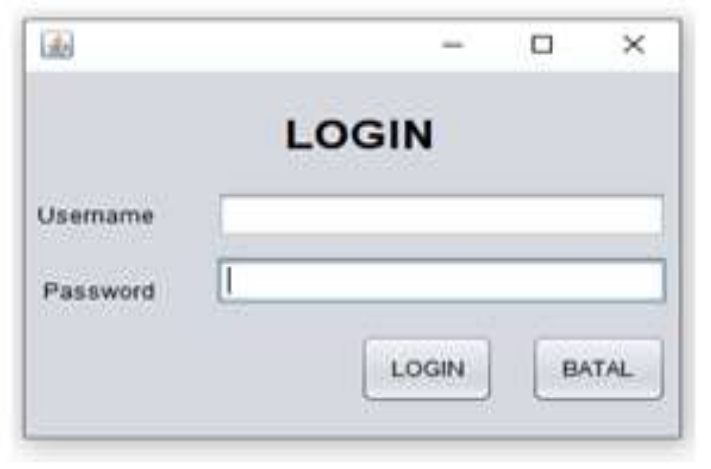

Gambar 2. Login 


\section{Tampilan menu utama}

From menu utama setelah login berhasil

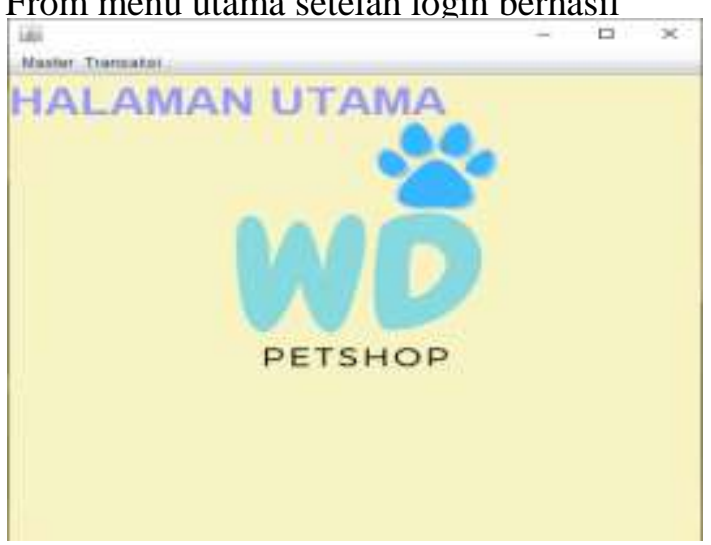

Gambar 3. Menu Utama

\section{Tampilan Form Hewan}

Tampilan from hewan untuk menambah, mengedit dan menghapus data hewan.

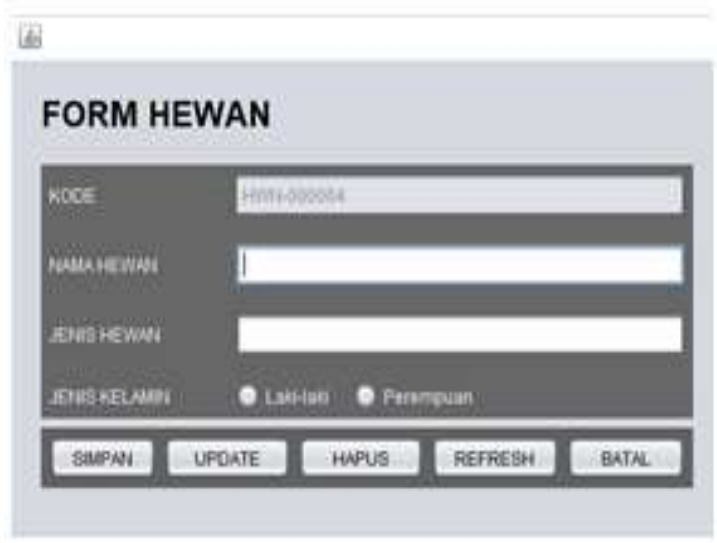

Gambar 4. Form Hewan

\section{Tampilan Form Data Kandang}

Tampilan from data kandang untuk menambah, mengedit dan menghapus data kandang.

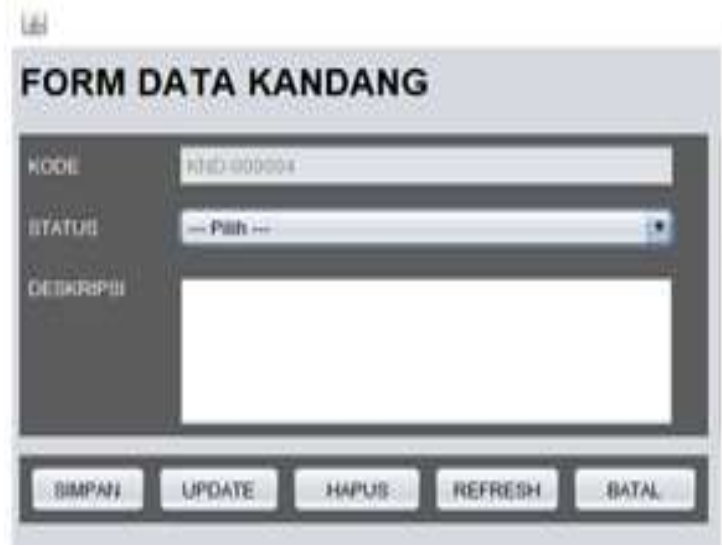

Gambar 5. Form Kandang
Tampilan Menu Karyawan

Tampilan from Karyawan untuk menambah, mengedit dan menghapus data Karyawan

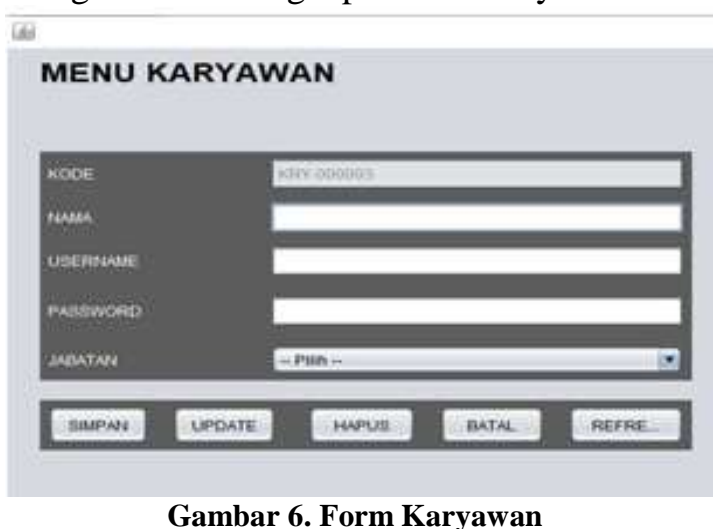

Tampilan Menu Paket

Tampilan From Paket untuk menambah, mengedit dan menghapus data Paket

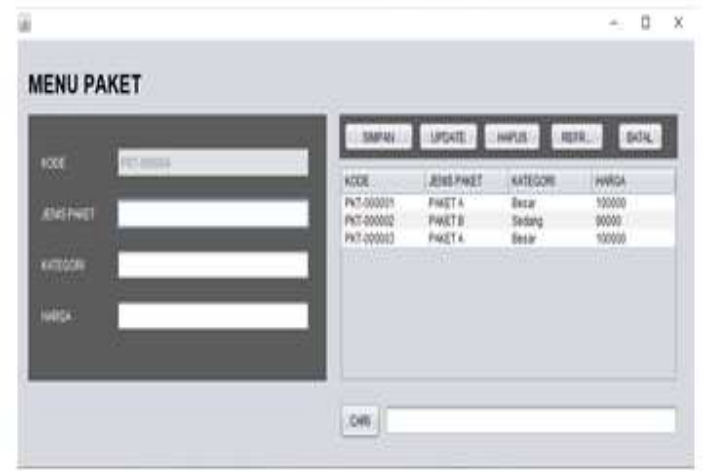

Gambar 7. Form Paket

\section{Tampilan Menu Pelanggan}

Tampilan From Pelanggan untuk menambah, mengedit dan menghapus data Pelanggan

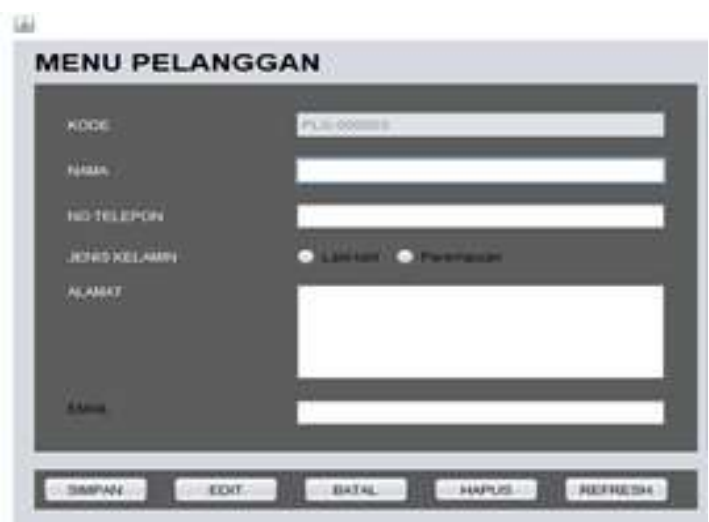

Gambar 8. Form Pelanggan 


\section{Tampilan Menu Penitipan}

Tampilan From Penitipan untuk menambah, mengedit dan menghapus data Penitipan

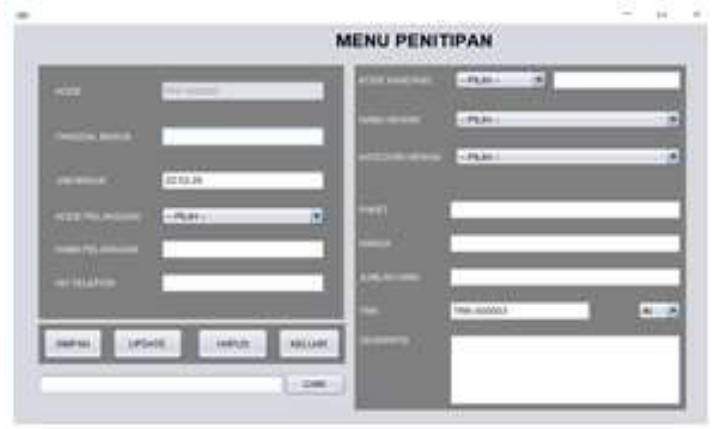

Gambar 9.Form Penitipan

Tampilan Menu Transaksi Pembayaran

Tampilan From Pembayaran untuk menambah, mengedit dan menghapus data Pembayaran

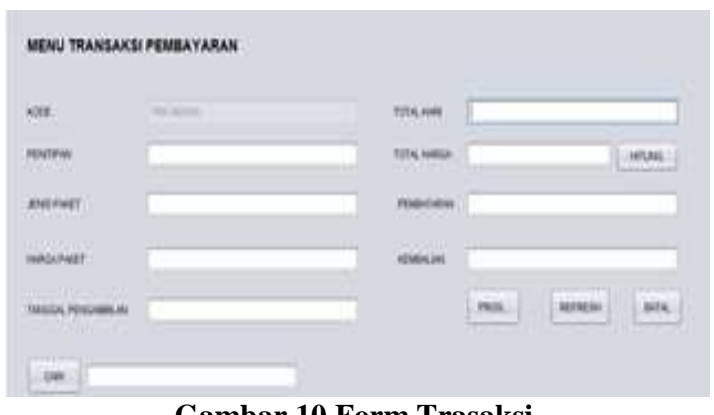

Gambar 10.Form Trasaksi

\section{Tampilan Laporan Pelanggan}

Pada tampilan ini menampilkan sebuah laporan data pelanggan yang berkunjung ke toko

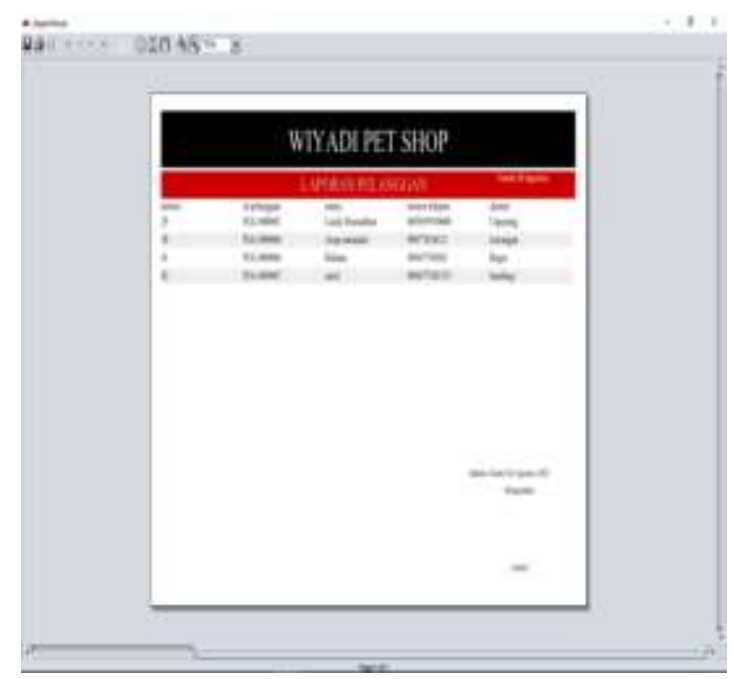

Gambar 11.Laporan Pelanggan
Tampilan Laporan Hewan

Pada tampilan ini menampilkan sebuah laporan data hewan yang di titipkan ke toko

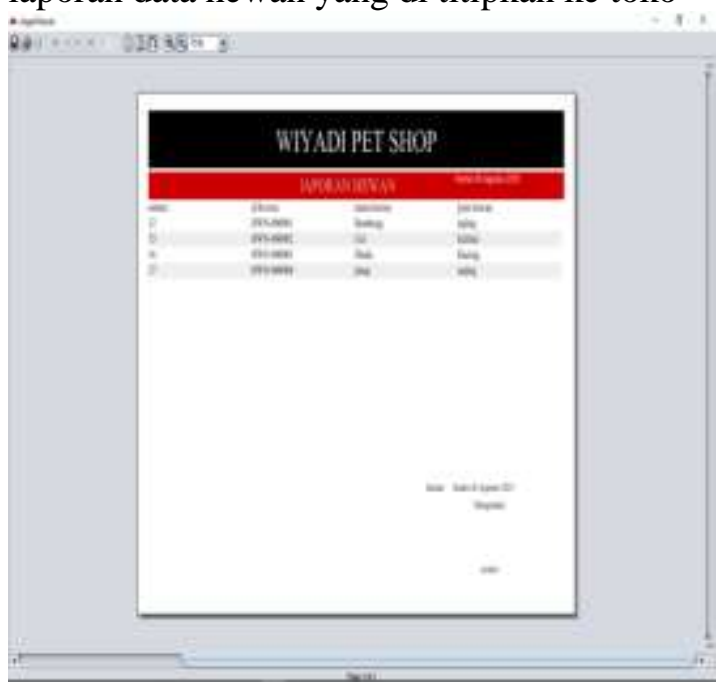

Gambar 12.Laporan Hewan

\section{SIMPULAN DAN SARAN}

Berdasarkan hasil penelitian yang penulis lakukan pada penitipan hewan Wiyadi Pet Shop, serta dari pembahasan pada bab-bab sebelumnya maka penulis dapat menarik kesimpulan sebagi berikut

1. Sistem yang berjalan seperti proses transaksi, pendataan, pembayaran serta laporan di Wiyadi Pet Shop masih menggunakan cara manual.

2. Sistem yang kini dilakukan secara manual akan memiliki banyak masalah serperti human error seperti pendataan tidak efektif dan efesien, resiko dokumen mudah rusak dan hilang, penyimpanan dokumen membutuhkan banyak ruang serta resiko admin salah perhitungan dalam bertransaksi dan pembuatan laporan. Sehingga pelanggan juga tidak mendapatkan bukti transaksi, kemudian nantinya akan sulit dipertanggung jawabkan dan pelanggan menjadi tidak mudah percaya.

3. Pembuatan sistem Aplikasi penitipian hewan yang secara terkomputerisasi ini, dapat meningkatkan efektifitas dan efesiensi dalam pendataan transaksi untuk admin dan mempermudah dalam pembuatan suatu laporan karena data yang dibutuhkan telah sesuai dengan yang di inginkan sehingga dapat mempercepat semua proses pelayanan. 
Dari kegiatan perancangan sistem yang dilakukan, demi tercapainya tujuan dan sasaran yang diharapkan oleh penulis. Maka penulis memberikan saran sebagai berikut:

1. Diperlukan adanya pelatihan kepada pengguna atau user sistem aplikasi penitipan hewan ini agar memahami dalam penggunaannya.

2. Perancangan sistem aplikasi penitipan hewan ini dapat di analisakan dan kemudian dikembangkan kembali dalam segi desain, penambahan fitur-fitur, serta penambahan database sesuai perkembangan dan kebutuhan pengguna atau user.

3. Dala penggunaan sistem yang terkomputerisasi ini diharapkan selalu melakukan back up data dari mulai perhari, perminggu, perbulan, sampai pertahun sehingga dapat meminimalisir hal-hal yang tidak diinginkan kedepannya.

\section{DAFTAR PUSTAKA}

Anggito, A., \& Setiawan, J. (2018). Metodologi Penelitian Kualitatif.

Chan. 2017. (2017). Membuat Aplikasi Database dengan PowerBuilder 12.6 dan MySQL. Jakarta: PT Alex Media Komputindo.

https://books.google.com/books?hl=id\& $\mathrm{lr}=\& \mathrm{id}=\mathrm{BC}$ IIDwAAQBAJ\&oi=fnd \&pg $=$ PP1\&dq=Chan.+2017.+Membuat+Ap likasi+Database+dengan+PowerBuilder +12.6+dan+MySQL.+Jakarta:+PT+Ale $\mathrm{x}+$ Media+Komputindo.\&ots=DfdFx $2 \mathrm{jo}$ Nx\&sig=_bSS15Qdbg1j5W6outp6Varh

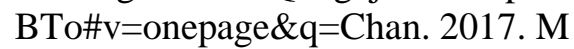

Fahrizal, I., Setiawan, H. S., Studi, P., Informatika, T., Gedong, K., Rebo, P., \& Timur, J. (2021). Perancangan aplikasi sistem informasi manajemen barang pada planet computer berbasis java netbeans. 02(04), 724-731.

Fiqri, Wildan (2017) Sistem Pelayanan Hewan Berbasis Web Berbasis Web Pada Zoom Pet Care. Diploma thesis, Universitas Komputer Indonesia.

Kurniawan, E., \& Syahputra, A. K. (2018). Perancangan Aplikasi Pemesanan Dan Pembayaran Berbasis Desktop Pada Percetakan UD. AZKA GEMILANG Menggunakan Metode Prototype. Seminar Nasional Raya, 9986(September), 105-110.

Lisnawanty. (2014). Uce Case Diagram;
Activity Diagram; Sequence Diagram; Deployment Diagram. 8-16. https://repository.bsi.ac.id/index.php/un duh/item/215571/File_10-Bab-II-

Landasan-Teori.pdf

Listiawan, T. (2016). Pengembangan Learning Management System (Lms) Di Program Studi Pendidikan Matematika Stkip Pgri Tulungagung. JIPI (Jurnal Ilmiah Penelitian Dan Pembelajaran Informatika), $\quad 1(01), \quad$ 14-22. Https://Doi.Org/10.29100/Jipi.V1i01.13 Rohman, F., Yanto, A. B. H. Y., \& Sutarsih, N. (2018). Rancang Bangun Sistem Informasi Ujian Online Berbasis Web Menggunakan Metode Waterfall (Studi Kasus: SMK Darma Nusantara Pandeglang). Indonesian Journal On Networking And Security, 7(3), 22-27. Http://Ijns.Org/Journal/Index.Php/Ijns/ Article/View/1530/1479

Supriyanta, \& Nurhayati, I. (2018). Sistem Informasi Penjualan Secara Online Studi Kasus Pada Mechin Petshop Yogyakarta. Journal On Networking And Security Volume 8 No 1 - 2018, 8(1), 1-6. Https://Ijns.Org/Journal/Index.Php/Ijns/ Article/View/1559/1496

Yusuf, D., Afrizal, T., \& Budiarto, A. (2021). Perancangan Sistem Aplikasi Pemesanan Lapangan Futsal Berbasis Java Pada Wirabujana Futsal Indramayu. Journal of Information System, Applied, Management, Accounting And Research (JISAMAR), $5(1)$, 125-131. Http://Journal.Stmikjayakarta.Ac.Id/Ind ex.Php/Jisamar/Article/View/347 